\title{
Black-White Disparities in Pediatric Asthma in Metropolitan Areas, 2015: Assessing the Roles of Residential Inequality and Segregation
}

\author{
Samantha Friedman \\ Associate Professor of Sociology \\ University at Albany, SUNY \\ Emily Rosenbaum \\ Professor of Sociology \\ Fordham University \\ Hui-shien Tsao \\ Research Scientist \\ Bureau of Research, Evaluation, and Performance Analytics \\ New York State Office of Children and Family Services \\ Recai Yucel \\ Professor of Biostatistics \\ Department of Epidemiology and Biostatistics \\ University at Albany, SUNY \\ Dan $\mathrm{He}$ \\ Doctoral Student \\ University at Albany, SUNY
}

September 29, 2019

\begin{abstract}
Little research has explored how black-white residential inequality and residential segregation are associated and moderate black-white disparities in pediatric asthma. This paper contributes to this limited literature by using data for children in the 2015 American Housing Survey Metropolitan samples. Controlling for black-white inequalities in residential characteristics, segregation, demographic, and socioeconomic characteristics, we find that the black-white disparity in pediatric asthma remains and slightly widens. We also find that the level of segregation, as measured by the index of dissimilarity and black isolation, moderates the association between children's race and asthma. In areas with lower levels of dissimilarity and black isolation, whites' predicted probabilities of asthma are greater than those of black children. However, when the index of dissimilarity is at least $60 \%$ and the black isolation is at least $50 \%$, the racial disparity reverses, and black children's predicted probabilities of asthma are significantly higher than those of whites.
\end{abstract}




\section{Introduction}

Asthma is increasing every year, and among children, it is the third leading cause of hospitalization in the United States (Centers for Disease Control and Prevention (CDC) 2019). It is the most common chronic illness among children in the United States (Pearlman et al. 2006); the CDC (2019) reported that blacks are two to three times more likely to suffer death from asthma than other racial and ethnic groups, and the prevalence of asthma is particularly high among blacks (Akinbami et al. 2009; Mendoza et al. 1991). Using data from the 1998-2008 National Health Interview Survey (NHIS), Mehta, Lee, and Ylitalo (2013) find that black children's rate of asthma was 1.5 times that of whites (17.54\% versus $11.66 \%)$. Many studies have also found that asthma has a higher than average prevalence among poor and inner-city residents (Canino, McQuaid, and Rand 2009; Williams, Sternthal, and Wright 2009).

Housing and neighborhood conditions have been linked to the prevalence of asthma. Substandard housing conditions - including the presence of dust mites, feces from cockroaches and mice, as well as mold - have all been shown to trigger asthma (Bashir 2002; Diaz et al. 2018; Ganesh et al. 2017; Kreiger and Higgins 2002; Mehta et al. 2018; Northridge et al. 2010; Rauh, Chew, and Garfinkel 2002; Vesper et al. 2013). The neighborhoods in which people reside have also been suggested to influence asthma although the precise mechanisms by which this occurs are not always clear (Arcaya et al. 2016; Alclala et al. 2019; Riley 2018).

Ironically, although residential segregation at the metropolitan level is touted to be important in impacting asthma (Boardman, Finch, and Hummer 2001; Williams at al. 2009) as well as individual health more generally (Acevedo-Garcia et al. 2003; Do et al. 2017; Osypuk and Acevedo-Garcia 2010), no research, to our knowledge, has examined its impact on asthma, overall, or on pediatric asthma. In a systematic review of social science and health literature 
conducted in 2008, Kramer and Hogue (2009) identified only 39 studies that explicitly examined the link between segregation and health outcomes. However, none of these studies examined asthma as an outcome. In a more recent review of the same literature, focusing on studies published between January 2003 and March 2014, Yang (2014) identified 33 articles that utilized multilevel modeling procedures to examine the impact of residential segregation on health outcomes. However, none of them explored asthma or pediatric asthma.

Using data from the 2015 American Housing Survey Metropolitan samples (AHS-MS), this study seeks to contribute to the literature by examining black-white disparities in pediatric asthma by explicitly considering the roles of racial residential inequality and levels of residential segregation as measured by the index of dissimilarity, black isolation, and hypersegregation. The AHS-MS data are uniquely suited for this paper because they contain data on housing units and the households living in them 25 metropolitan-specific samples (shown in Appendix Table 1) and on the presence of asthma among children ages 6 to 17. In addition, the 2015 data contain information on the housing quality of the unit (e.g., the presence of cockroaches and rodents), other residential characteristics (e.g., housing tenure and age, neighborhood quality), socioeconomic, demographic, and other health-related information for household members (e.g., whether anyone smoked in the unit).

Using these data, our paper seeks to fulfill five main objectives: (1) document the blackwhite disparities in pediatric asthma; (2) characterize the nature of black-white differences in residential characteristics, segregation, and demographic and socioeconomic characteristics of households that might contribute to the black-white disparities in pediatric asthma; (3) examine the extent to which black-white disparities in pediatric asthma remain after controlling for differences in residential characteristics and segregation as well as the demographic and 
socioeconomic characteristics of households; (4) examine whether residential segregation is associated with pediatric asthma as measured by the index of dissimilarity, the black isolation index, and hypersegregation; and (5) examine whether the effect of children's race on asthma is moderated by the level of segregation in the metropolitan area. By examining the role of residential segregation in being associated with asthma and in moderating the effect of children's race on asthma, our study seeks to make a significant contribution to the literature where the explicit focus on residential segregation as affecting asthma has been absent.

\section{Background}

Racial residential segregation remains a prominent feature in metropolitan America, even more than 45 years after the passage of the Fair Housing Act (Logan and Stults 2011). Historically, the forces and public policy choices that generated high levels of black-white residential segregation have also led to the concentration of blacks in poorer-quality housing, by constraining blacks' housing choices to aging and deteriorating inner-city neighborhoods (Massey and Denton 1993). For example, the discriminatory underwriting practices institutionalized by the Home Owners Loan Corporation (HOLC) in 1933 and subsequently adopted by the Federal Housing Administration (FHA) starved inner-city neighborhoods of needed capital and, along with the Veterans Administration's Home Loan Guarantee Program, hastened the mass postwar exodus of whites to the suburbs (Jackson 1985). The FHA provided very limited funds towards the reconstruction of existing housing stock or construction of multifamily homes and instead devoted the vast majority of its financing to new housing in suburbs. 
At the same time, white residents formed neighborhood associations and implemented restrictive covenants, which preserved the racial homogeneity of their neighborhoods so that blacks could not settle there (Massey and Denton 1993: 36). Real estate agents adopted practices of blockbusting and racial steering, which also strengthened the color line between whites and blacks and perpetuated residential segregation (Massey and Denton 1993). Taken together, these historical forces and public policy choices effectively kept blacks out of suburbs and neighborhoods with better quality housing and better amenities (e.g., good schools, access to jobs, better quality healthcare).

There is no doubt that contemporary black access to better quality housing and neighborhoods has been shaped by these historical forces, but particularly so in older metropolitan areas in the Northeast and Midwest (e.g., New York, Chicago, Philadelphia, Milwaukee, Cleveland). The persistence of racial inequalities in residential attainment is abetted by contemporary segregating forces, including housing discrimination and zoning policies. Results from the 2012 Housing Discrimination Study (HDS) revealed that black home seekers in the rental and sales markets were told about $11.4 \%$ and $17 \%$ fewer homes, respectively, and shown $4.2 \%$ and $17.7 \%$ fewer homes, respectively, than their white counterparts (Turner et al. 2013). Density zoning has been causally linked to explaining variation in inter-metropolitan black-white segregation levels, with areas that have low-density zoning policies to have higher rates of black-white segregation than those that are more supportive of high-density zoning policies (Rothwell and Massey 2009; Rugh and Massey 2014). In the former areas, blacks are much more likely to live in central-city neighborhoods.

There are many large metropolitan areas that have lower contemporary rates of blackwhite residential segregation such as Dallas, Charlotte, Phoenix, and Seattle. The ecological 
structure of newer metropolitan areas is less conducive to residential segregation, largely because they followed a growth pattern guided by annexation, with central cities incorporating areas on the periphery, and a far greater share of their overall housing stock was built after 1969, when discrimination in the housing market became illegal (Farley and Frey 1994). As a result, newer metropolitan areas are less likely than are older areas to consist of a densely populated urban core surrounded by suburbs, and thus a multitude of separate taxing and policy-making entities (Farley and Frey 1994; Massey and Denton 1993; Rugh and Massey 2014).

These structural differences in the nature of segregating forces across metropolitan areas are no doubt related to the nature of the housing and residential options available to blacks, relative to whites. As discussed above, blacks have been more likely than whites to live in central cities, and this disparity continues (Timberlake, Howell, and Staight 2010). In terms of housing, in metropolitan America, blacks are more likely than whites to occupy poor-quality housing - housing that has at least one of the following problems: water leaks, heating or toilet breakdowns, the presence of rodents, cracks/holes in the walls or ceiling, or large patches of peeling paint or plaster -- controlling for relevant socioeconomic factors (Friedman and Rosenbaum 2004). Although not explicitly examined, blacks' housing choices are likely to be more open and of much better quality in newer, more recently developed and less segregated metropolitan areas than those in more segregated areas with an older housing stock. Research on residential segregation has shown that metropolitan areas with greater shares of newer housing supply tend to have lower levels of black-white segregation than areas with older housing stock (Iceland and Sharp 2013; Timberlake and Iceland 2007).

The neighborhoods in which blacks reside are inferior in quality, on average, relative to those where whites live, even after accounting for differences in socioeconomic status and 
demographic factors (Sampson 2012). Black middle-class households often live in neighborhoods with as much crime and violence as their less-affluent counterparts (PattiloMcCoy 1999). Households with children are not shielded from such environments. Rosenbaum and Friedman (2001) find that in New York City, black households with children are significantly more likely than white households with children to live in neighborhoods with higher rates of juvenile detention, teenage fertility, welfare use, and student underperformance in schools.

How do such disparities in residential attainment translate into disparate rates of pediatric asthma between blacks and whites? In the broader literature, researchers have found that blacks, relative to whites, are disproportionately exposed to the types of substandard housing problems that trigger asthma; this appears to be a primary pathway whereby race influences the odds of pediatric asthma (Gold and Wright 2005; Rosenbaum 2008). As mentioned earlier, housing conditions such as dampness and feces from rodents and cockroaches are directly linked to the prevalence of asthma (Bashir 2002; Diaz et al. 2018; Ganesh et al. 2017; Kreiger and Higgins 2002; Mehta et al. 2018; Northridge et al. 2010; Rauh, Chew, and Garfinkel 2002; Vesper et al. 2013). The fact that minorities, and blacks in particular, are more likely than whites to reside in homes with such substandard housing conditions explains part of the reason why they have higher rates of asthma than whites (Rosenbaum 2008).

Whether other residential factors impact the prevalence of pediatric asthma remains to be seen. The neighborhoods in which people reside have been suggested to influence asthma. Katz, Kling, and Liebman (2001) found a 50 percent drop in asthma attacks among children in the Moving to Opportunity Program (MTO) in Boston when they moved from public housing in high-poverty areas to better quality housing in less poor neighborhoods. The levels of collective 
efficacy in the neighborhoods and the trust that parents place with neighbors to keep their children safe have also been found to impact the prevalence of asthma, with more collective efficacy and trust being associated with lower levels of asthma (Cagney and Browning 2004; Camacho-Rivera et al. 2014). Researchers have posited that the extreme and chronic stress that results from living in areas characterized by disamenities, including high levels of social and physical disorder, can increase residents' vulnerability to a wide range of health conditions, including asthma (Camacho-Rivera et al. 2014; DePriest, Butz, and Thorpe 2018; Eldeirawi et al. 2016; Gold and Wright 2005). However, one recent study finds that inner-city residence has no impact on pediatric asthma (Keet et al. 2015).

The preceding review of the literature suggests several hypotheses that will be tested in our analyses. Given the past research that has been done focused on the linkages among race, housing conditions, and asthma, we expect that low-quality housing conditions will be positively associated with pediatric asthma, controlling for other relevant characteristics. Because of the variation in the ecology of metropolitan areas, we expect that housing tenure, age of the housing stock, and the neighborhood quality will also be important in explaining black-white disparities in pediatric asthma. Given the extensive differences in the way that highly segregated metropolitan areas formed historically, we expect that the black-white disparity in pediatric asthma will be moderated by the level of segregation in the metropolitan area. We expect to find that the black-white disparity in pediatric asthma will be greater in areas with higher levels of residential segregation and will be smaller in areas with lower levels of segregation. 


\section{Data and Methods}

Our analyses of black-white disparities in pediatric asthma are based on data from 25 independent, metropolitan area samples comprising the 2015 American Housing Survey Metropolitan Sample (AHS-MS), which is collected by the U.S. Department of Housing and Urban Development (HUD) and the U.S. Census Bureau (see Appendix Table 1 for the areas that comprise these 25 samples). In 2015, a new sample was collected in each of these 25 metropolitan areas to represent the occupied and vacant housing units within these Core Based Statistical Areas (CBSAs), defined by the Office of Management and Budget (U.S. Census Bureau and HUD 2018). The response rates within the 2015 AHS-MS samples was at least 71.5\%, and each sample was comprised of about 3,000 housing units (U.S. Census Bureau and HUD 2018: Table 2.2).

We take advantage of data from the 2015 AHS-MS because the survey included a "healthy homes" topical module. Households with children ages 6 to 17 were asked to report for each child in the home whether they had ever been told by a health professional that child has asthma. This question is similar to those in found in other data, like the National Health Interview Survey, and used in other research on asthma (e.g., Keet et al. 2015; Mehta et al. 2013; Pearlman et al. 2006; Rosenbaum 2008). Because the AHS contains many questions on housing quality and residential circumstances, the addition of the asthma question makes the data ideal for our study. Indeed, no other national-level dataset, to our knowledge, facilitates the ability to study these phenomena together. From these data, we construct a child-level dataset, comprised of children in households with children ages 6 to 17, to examine racial differences in asthma.

To the AHS-MS child-level data, we merge data on the residential segregation present in these metropolitan areas. This allows us to directly examine the impact of residential 
segregation on pediatric asthma, which has heretofore been absent in the literature. To create measures of residential segregation, which we discuss in greater detail below, we use population counts by race and ethnicity from the 2010 Summary File 1 decennial census. We extract these data at the census-tract level of analysis within our 25 metropolitan areas defined at the CBSA level.

Our central dependent variable is derived from the question on asthma. As previously stated, the householder was asked whether a health provider has ever told her/him that any child in the home has asthma. If the householder said yes, the AHS field representative went through the household roster and asked the householder to identify the children with asthma. Based on this assessment, we created a dummy variable, for each child, indicating whether the child has asthma.

Our key independent variable is the child's race. We use a dummy variable to gauge whether the child is non-Hispanic white or non-Hispanic black (hereafter referred to as white or black). We also control for whether the child is male versus female and the child's age. Both characteristics have been linked to asthma in previous research $(*$ cite*).

Another key independent variable in our analysis gauges the residential segregation of the metropolitan area. We measure residential segregation using two commonly used variables -the index of dissimilarity and the isolation index (Logan and Stults 2011). We also use a dummy variable indicating whether the metropolitan area is considered to be hypersegregated on at least four measurable dimensions of segregation (Massey and Tannen 2015).

With respect to measuring the quality of the housing and neighborhood occupied by the child and the region, we create a number of measures. A variable gauging the number of maintenance deficiencies in the housing unit is constructed by counting the following housing 
conditions present in the unit, all of which could directly or indirectly promote asthma -evidence of roaches or rodents in the unit; whether the unit has had toilet or heating breakdowns; and whether the unit has cracks/holes in the walls or ceiling, large patches of peeling paint/broken plaster, or water leaks (from the inside of the home). In addition, we include dummy variables indicating -- whether the home is rented and the year the unit was built (before 1970 (reference group); between 1970 and 2000; in 2000 or later). With respect to the neighborhood conditions, we create a dummy variable from a question that asks householders about whether the neighborhood has a lot of serious crime ( $1=$ agree; $0=$ disagree), as higher levels of social disorder have been linked to asthma in previous research (Cagney and Browning 2004; Camacho-Rivera et al. 2014). Finally, we create three dummy variables for region (Midwest; South; and West, with Northeast as the reference group) to control for variation in children's geographic location.

We include a number of other variables in our multivariate analyses that measure demographic and socioeconomic characteristics of households that might explain why blackwhite disparities exist in pediatric asthma. The demographic indicators include dummy variables measuring whether the household is headed by a married couple and whether the householder is foreign born. Socioeconomic status is gauged by several variables. Education is represented by four dummy variables indicating whether the households has 1) less than a high school degree (reference); 2) a high school degree; 3) some college education; and 4) at least a Bachelor's degree. We control for household income and include a dummy variable gauging the presence of at least one smoker in the household.

To fulfill our research objectives, we first conduct descriptive analyses examining the black-white disparity in the prevalence of pediatric asthma within our metropolitan data. 
Second, we examine black-white differences in residential segregation, residential characteristics, and demographic and socioeconomic variables just discussed. Our bivariate analyses are presented for complete data and exclude cases via listwise deletion if they have missing data on any of our independent or dependent variables. We lose 627 cases because of missing data (i.e., from 7732 observations to 7105 observations), and the bulk of the missing cases are found for our key dependent variable gauging whether the child has ever had asthma. Arbitrary patterns of missing values seen on multiple variables are known to impose a threat to statistical inferences (Rubin 1987; Allison 2001). Inference by multiple imputation is used to allow a full use of the observed data and to formally incorporate uncertainty due to missing data into our inferences. Multiple imputation routines take into account the data structure and multivariate relationships. Specifically, we use the R package, JOMO, based on the methodology developed by Quartagno and Carpenter (2016). This package facilitates Markov Chain Monte Carlo (MCMC) techniques to draw multiple imputations in multilevel applications for mixtures of variables subject to missing values on multiple observational level-1 or level-2 units, which fits our data structure well. The underlying imputation model is a joint model with normal latent variables for the categorical variables. Five imputed datasets are drawn from the posterior predictive distribution implied by this imputation model. Each of the imputed datasets is then analyzed using the multivariate analyses described in the next paragraph, leading to five sets of estimates and standard errors. These standard errors explicitly incorporate the variability in the predictive distribution of missing data (hence uncertainty due to missing data) into the traditional estimate of sampling variability. Using the rules defined by Rubin (1987), we combine these estimates and standard errors, and present them in the Table 2, using R. 
Multilevel logistic regression analysis is used to identify the association between children's race and whether they have ever had asthma as well as the association between residential segregation and whether the child has had asthma. We employ three models, with each using one of the residential segregation measures defined earlier. Then, for each model, we add an interaction term between the child's race and the segregation measure, in order to examine whether the association between the child's race and whether s/he has ever had asthma is moderated by the segregation within the metropolitan area. In all the aforementioned analyses, robust standard errors are employed to correct for potential autocorrelation of the results due to clustering of respondents in metropolitan areas. We use sampling weights (scaled down to maintain un-weighted cell sizes) to correct for sampling design effects and potential under coverage. We should note that given the cross-sectional nature of these data, we cannot draw any inferences about the causal relationships between our independent and dependent variables.

\section{Results}

What is the prevalence of pediatric asthma of whites and blacks in our metropolitan samples? Table 1 addresses this question, presenting data on children 6 to 17 years of age, overall, and by race within the AHS-MS data. Column 1 shows that among children in the metropolitan samples, 13\% have ever had asthma. Columns 2 and 3 reveal that black children are significantly more likely than white children to have ever had asthma. The black-white disparity in children with asthma is about 5.5 percentage points.

\section{$<$ TABLE 1 HERE $>$}

The remainder of Table 1 presents data on children, overall, and by race in terms of their child-level and residential characteristics as well as the demographic and socioeconomic 
characteristics of the person in their home who is the householder or from the household itself. With respect to child-level characteristics, white children are significantly more likely to be males than black children, but there is no racial difference in their ages. Black children live in more segregated areas and have lower levels of residential quality than white children. For blacks, the average index of dissimilarity in their metropolitan areas is 66.81 and the average level of isolation is 63.99 , both of which are significantly higher than the respective measures for their white counterparts. However, no racial difference exists with respect to their levels of hypersegregation. With respect to the number of maintenance deficiencies, black children had an average of .81 deficiencies, about 1.7 times the average for whites (.47). It is likely that this poorer housing quality is linked to black children's higher levels of asthma. Black children are 2.9 times as likely as white children to live in rental housing and are significantly more likely to live in older housing stock, disparities that undoubtedly related to blacks' poorer quality housing conditions. Not surprisingly, black children live in neighborhoods that are five times more likely than those of white children to be considered as having a lot of serious crime. Black children are also much more likely than white children to live in the South, which is consistent with black migration patterns back to the South in recent decades (Hunt et al. 2008, 2013).

The remaining section of Table 1 reveals black-white inequalities in household demographic and socioeconomic characteristics that enable white children to have significant advantages over black children in terms of their housing and health. For example, white children are 1.9 times as likely as black children to live in households headed by a married couple. Moreover, white householders are significantly likely to be more educated and have higher incomes than their black counterparts. Finally, white households are significantly less likely than black households to contain at least one smoker. 
The questions to which we now turn is: 1) whether the racial difference in asthma among children persists after controlling for the aforementioned racial differences in residential, demographic, and socioeconomic characteristics; and 2) whether residential segregation affects pediatric asthma, controlling for relevant factors. Table 2 addresses these questions by presenting the logistic regression coefficients from three multilevel logistic regression models that each use a different measure of residential segregation. Regardless of the segregation measure used, columns 1, 3, and 5 of Table 2 show that black children are 1.55 times as likely (i.e., $\exp (.438)=1.55)$ as white children to have ever had asthma, controlling for differences in residential, demographic, and socioeconomic differences. Thus, the results from the multivariate analyses reveal that adding the control variables slightly widens the racial gap in pediatric asthma from 1.49 (Table $1-16.98 \%$ versus $11.41 \%$ ) to 1.55 . With respect to our measures of segregation and their influence on asthma, none of them has a direct, significant effect on asthma.

\section{$<$ TABLE 2 HERE $>$}

Our next analytical objective is to examine whether the association between child's race and asthma is moderated by the metropolitan-level segregation. Columns 2, 4, and 6 reveal that this relationship is moderated when considering segregation as measured by the index of dissimilarity and the isolation index but is not affected by hypersegregation. Figure 1 graphs the predicted probabilities of asthma by the child's race and the level of dissimilarity in the metropolitan area. The figure reveals that at levels of dissimilarity that are below $55 \%$, white children are significantly more likely than black children to have reported ever having asthma. However, the racial disparity reverses and magnifies dramatically at dissimilarity scores of $60 \%$ and higher. Notably, when the index of dissimilarity is $65 \%$, black children's predicted 
probability of ever having reported to have asthma is .09 , a rate 1.4 times higher than their white counterparts. When the index of dissimilarity is $75 \%$, black children's predicted probability of asthma is 1.9 times as high as white children's probability.

Figure 2 graphs the predicted probabilities of asthma by the child's race and black isolation scores in the metropolitan areas, as derived from using model 4 in Table 2. The figure reveals that when black isolation scores are below 50\%, white children are significantly more likely than black children to have reported ever having asthma. However, when the black isolation score is at or above $50 \%$ the racial disparity reverses and magnifies as black isolation increases. For example, when the black isolation score is $65 \%$, black children's predicted probability of asthma is 1.6 times that of white children. When the isolation score is $70 \%$, black children's predicted probability of every having asthma is 2.2 times that of white children.

How do the other residential characteristics affect pediatric asthma? As suspected and consistent with previous research, adverse housing conditions are significantly related to the likelihood of ever having asthma among children. Columns 1 through 6 of Table 2 show that in every model of pediatric asthma the number of maintenance deficiencies is positively related to the log odds of asthma, controlling for other relevant factors. In addition, across all models, children living in housing that was built in 2000 or later are less likely to have asthma than children living in housing built before 1970, controlling for other characteristics. Children living in households whose householders agreed with the statement that their neighborhood has a lot of serious crime also had higher log odds of asthma than children whose householders did not agree with the statement about their neighborhood having a lot of serious crime. This was a finding also statistically significant across all models in Table 2. 
In considering the demographic and socioeconomic variables in Table 2, children living in married households and with householders who are immigrants and who are more educated have significantly lower log odds of ever having been reported to have asthma, across all of the models, than children living in non-married households and with householders who are not immigrants and who are less educated, controlling for other relevant factors. The two findings that did not conform to our expectations were those concerning the effects of household income and whether there was at least one smoker in the household. Table 2 shows that household income was consistently, positively related to the log odds of pediatric asthma across all models, and the presence of at least one smoker in the householder significantly decreased the log odds of pediatric asthma, controlling for other factors. Sensitivity analyses will be performed to check these results. For example, it is probably worth including a measure of whether the children's poverty status affects their log odds of asthma. At present, our definition of including a smoker in the home includes people who smoke infrequently. Perhaps that is affecting our results.

\section{Discussion}

The primary goal of this paper was to examine the roles that residential inequality and residential segregation play in affecting racial disparities in pediatric asthma in metropolitan America. To fulfill this main goal, the analysis focused on fulfilling five main objectives. First, and consistent with other studies using national-level data, we found that black children were significantly more likely than white children to have reported to ever have had asthma.

Our second objective was to examine the extent to which the black-white disparity in pediatric asthma reflected racial inequalities in residential characteristics and segregation as well as differences in demographic and socioeconomic factors between blacks and whites. Based 
upon our descriptive analyses, we found that the black-white disparity in pediatric asthma was attributable to the significant residential inequalities found between blacks and whites, as well as to differences in demographic characteristics and socioeconomic status that put blacks at a significant disadvantage, relative to whites, in achieving access to better quality housing and in maintaining better quality health.

Our third objective was to examine the extent to which racial disparities in the pediatric prevalence of asthma are reduced or changed with controls for differences in residential characteristics and segregation as well as the demographic and socioeconomic characteristics of households. Using AHS-MS data, we found that the statistically significant black-white disparity in pediatric asthma was not eliminated by controlling for such variables but instead was slightly widened in magnitude. The multilevel logistic regression analyses also revealed that although residential segregation was not directly associated with pediatric asthma, fulfilling our fourth objective, other adverse housing conditions were significantly related, including maintenance deficiencies, year the housing was built, and reports of the presence of serious crimes in the neighborhood. In addition, the demographic and socioeconomic characteristics significantly affected the log odds of the prevalence of pediatric asthma such as the marital status, nativity status, and educational level of the householder.

The fifth and final goal of our analyses was to examine whether the effect of children's race on asthma is moderated by the level of segregation in the metropolitan area. We found that indeed this was the case. The level of segregation, as measured by the index of dissimilarity and black isolation, moderates the association between children's race and asthma. In areas with lower levels of dissimilarity and black isolation, whites' predicted probabilities of asthma are greater than those of black children. However, when the index of dissimilarity is at least $60 \%$ 
and the black isolation is at least $50 \%$, the racial disparity reverses, and black children's predicted probabilities of asthma are significantly higher than those of whites.

Taken together, these results have significant implications for black children, as the majority of metropolitan blacks (53.1\%) in the U.S. live in metropolitan areas with levels of segregation of at least $60 \%$ (Massey and Tannen 2015). It is likely that the share of black children living in segregated metropolitan areas is even higher because black female-headed families, with whom $49 \%$ of black children live (Child Trends Databank 2015), face higher levels of residential segregation than black married families (Friedman et al. 2019). Our results suggest that ignoring the impact of the residential segregation of the metropolitan area in which children live misses an important determinant of racial disparities in pediatric asthma.

These findings also have important theoretical implications for the study of racial disparities in pediatric asthma. The results suggest that residential inequality and segregation are both important and likely work together in explaining black-white disparities in pediatric asthma. The disadvantages in housing conditions experienced by blacks contribute to their higher rates of pediatric asthma. Moreover, the way that historical and contemporary forces underlying residential segregation have ecologically shaped the differential access that blacks have to better quality housing, relative to whites, appears to be significant in influencing black-white disparities in asthma. Up until our study, no research, to our knowledge, has explicitly examined how residential segregation moderates the effect of race on pediatric asthma.

Our findings clearly point to the need to examine housing conditions and other residential circumstances in the context of residential segregation, rather than in isolation. In the urban sociological literature, much theoretical and empirical work has shown how residential segregation shapes black-white disparities in residential location. However, research on the role 
of residential segregation in influencing health disparities generally neglects to incorporate this strand of research when examining these disparities. Nowhere is this more relevant than in the study of asthma. Asthma has been clearly connected to housing conditions. By ignoring the role that segregation plays in creating racial disparities in housing, it is likely that past research has underestimated the role that housing conditions play in the association between race and asthma.

Our study should serve as a point of departure for additional research so that more can be done to better document the impact of residential segregation on the relationship between race and pediatric asthma. Future analyses should explore other aspects of segregation that might also indirectly impact the prevalence of pediatric asthma besides housing conditions, housing tenure, and neighborhood crime. For example, it would be extremely useful to include more measures gauging the environmental aspects of neighborhoods in which households live to further explore the role that segregation plays. It is likely that racial disparities in exposure to more traffic and lower air quality are more prevalent in highly segregated areas where housing is concentrated than is the case in less segregated areas. It would also be worth exploring how residential segregation mediates the effect of race on pediatric asthma. It is likely that racial disparities in pediatric asthma could be completely explained by racial differences in residential inequality in metropolitan areas with higher levels of residential segregation and a constrained housing market than in areas with lower levels of residential segregation.

Future research should also seek to correct some of the other limitations present in the current analysis. For example, future analyses should be done using other indicators of asthma, including its severity. The data in the AHS-MS are quite limited. Subsequent studies should use data on more metropolitan areas as well as on neighborhood-level factors, particularly objective characteristics (e.g., poverty, crime) that shape residential segregation, residential inequality, and 
asthma. The restricted-use version of the 2015AHS national-level data would be ideal for this purpose because it would cover a wider range of metropolitan areas than is present in our data. In addition, future research should consider whether residential mobility out of such segregated environments reduces pediatric asthma.

In spite of these limitations, the findings here echo those of previous research in touting the importance of residential segregation in creating racial disparities in health (Acevedo-Garcia et al. 2003; Boardman, Finch, and Hummer 2001; Do et al. 2017; Osypuk and Acevedo-Garcia 2010; Williams at al. 2009). However, our study goes beyond previous research and maintains that simply controlling for the racial composition in neighborhoods is insufficient in gauging the impact of metropolitan-level segregation such outcomes and particularly in focusing on asthma. Segregation constrains the housing choices of blacks and relegates them to living in central cities. Such constraints result in blacks living in poorer quality housing than whites, and in the end, black children suffer from poorer health consequences.

Given that minority births are outpacing white births, examining the quality of where minority children live as well as their health outcomes will be particularly important, as minorities collectively become the majority group in American society (U.S. Census Bureau 2017). Moreover, although levels of black-white residential segregation are declining, the average level of segregation is still in the high range (Logan 2013), and the majority of blacks live in segregated metropolitan areas (Massey and Tannen 2015). If such residential inequalities and health disparities persist, this will have implications for how inequality may be transmitted across future generations of blacks in the U.S. 


\section{References}

Acevedo-Garcia, Dolores., Kimberly A. Lochner, Theresa L. Osypuk, and S.V. Subramanian. 2003. "Future Directions in Residential Segregation and Health Research: A Multilevel Approach.” American Journal of Public Health 93:215-221.

Adelman, Robert. 2004. "Neighborhood Opportunities, Race, and Class: The Black Middle Class and Residential Segregation." City and Community 3:43-63.

Akinbami Lara J, Jeanne E. Moorman, Paul L. Garbe, and Edward J. Sondik. "Status of Childhood Asthma in the United States, 1980-2007." Pediatrics. 2009;123(Supplement 3):S131-S145.

Alba, Richard D., John R. Logan, and Brian J. Stults. 2000. "How Segregated are Middle-Class African Americans?” Social Problems 47(4):543-558.

Alcala, Emanuel, Paul Brown, John A. Capitman, Mariaelena Gonzalez, and Ricardo Cisneros. 2019. "Cumulative Impact of Environmental Pollution and Population Vulnerability on Pediatric Asthma Hospitalizations: A Multilevel Analysis of CalEnviroScreen." International Journal of Environmental Research and Public Health 16(15):2683.

Allison, Paul D. 2001. Missing Data. Quantitative Applications in the Social Sciences Series. Thousand Oaks, CA: Sage Publications, Inc.

Arcaya, Mariana C., Reginald D. Tucker-Seeley, Rockli Kim, Alina Schnake-Mahl, Marvin So, and S. V. Subramanian. 2016. "Research on Neighborhood Effects on Health in the United States: A Systematic Review of Study Characteristics." Social Science \& Medicine 168:16-29.

Bashir, Samiya. 2002. "Home is Where the Harm is: Inadequate Housing as a Public Health Crisis." American Journal of Public Health 92(5):733-738.

Boardman, Jason, Brian Finch, and Robert Hummer. 2001. "Race/Ethnic Differences in Respiratory Problems among a Nationally Representative Cohort of Young Children." Population Research and Policy Review 20:187-206.

Breen, Richard, Kristian Bernt Karlson, and Anders Holm. 2013. "Total, Direct, and Indirect Effects in Logit and Probit Models.” Sociological Methods and Research 42(2):164-191.

Cagney, Kathleen A. and Christopher R. Browning. 2004. "Exploring Neighborhood-level Variation in Asthma and other Respiratory Diseases: The Contribution of Neighborhood Social Context." Journal of General Internal Medicine 19: 229-236.

Camacho-Rivera, Marlene, Ichiro Kawachi, Gary G. Bennett, and S.V. Subramanian. 2014. "Perceptions of Neighborhood Safety and Asthma among Children and Adolescents in Los Angeles: A Multilevel Analysis." PLOS ONE 9(1): 1-7. 
Canino Glorisa, Elizabeth L. McQuaid, Cynthia S. Rand. 2009. "Addressing Asthma Health Disparities: a Multilevel Challenge.” Journal of Allergy and Clinical Immunology. 123(6):1209-1217.

Centers for Disease Control and Prevention (CDC). 2019. "National Asthma Control Program." Retrieved August 19, 2019 (https://www.cdc.gov/nceh/information/asthma.htm).

Charles, Camille Zubrinsky. 2003. “The Dynamics of Racial Residential Segregation.” Annual Review of Sociology 29:167-207.

Child Trends Databank. 2015. Family Structure: Indicators on Children and Youth. Bethesda: MD, Child Trends. Available from: http://www.childtrends.org/?indicators=familystructure.

Diaz Lozano Patino, Ernesto and Jeffrey A. Siegel. 2018. "Indoor Environmental Quality in Social Housing: A Literature Review.” Building and Environment 131:231-41.

DePriest, Kelli, Arlene Butz, and Roland J. Thorpe. 2018. "The Relationship Between Neighborhood Safety and Children's Asthma: An Integrative Review." Journal of Pediatric Health Care 32(6):600-611.

Do, D. Phuong, Reanne Frank, and John Iceland. 2017. "Black-white metropolitan segregation and self-rated health: Investigating the role of neighborhood poverty." Social Science \& Medicine 187:85-92.

Eldeirawi, Kamal, Colin Kunzweiler, Natalya Rosenberg, Barth Riley, Yan Gao, Jennifer Hebert-Beirne, Shannon Zenk, Elizabeth Tarlov, and Victoria Persky. 2016. "Association of Neighborhood Crime with Asthma and Asthma Morbidity among Mexican American Children in Chicago, Illinois." Annals of Allergy, Asthma \& Immunology 117(5):502507.e1.

Farley, Reynolds and William H. Frey. 1994. "Changes in the Segregation of Whites from Blacks during the 1980s: Small Steps Toward a More Integrated Society." American Sociological Review 59:23-45.

Friedman, Samantha and Emily Rosenbaum. 2004. "Nativity-Status Differences in Access to Quality Housing: Does Home Ownership Bring Greater Parity?" Housing Policy Debate 15(4): 865-901.

Friedman, Samantha, Colleen Wynn, and Hui-shien Tsao. 2019. "The Influence of Family Structure and Children on Racial and Ethnic Residential Segregation.” Unpublished manuscript. 
Ganesh, Bhargavi, Corianne Payton Scally, Laura Skopec, and Jun Zhu. 2017. "The Relationship between Housing and Asthma among School-Age Children." Research Report. Washington, DC: Urban Institute.

Gold, Diane R. and Rosalind Wright. 2005. "Population Disparities in Asthma." Annual Review of Public Health 26:89-113.

Hunt, Larry L., Matthew O. Hunt, and William W. Falk 2008. "Who is Headed South? U.S. Migration Trends in Black and White, 1970-2000.” Social Forces 87(1):95-119.

Hunt, Matthew O., Larry L. Hunt, and William W. Falk. 2013. "Twenty-First-Century Trends in Black Migration to the U.S. South: Demographic and Subjective Predictors." Social Science Quarterly 94(5):1398-1413.

Iceland, John and Gregory Sharp. 2013. "White Residential Segregation in U.S. Metropolitan Areas: Conceptual Issues, Patterns, and Trends from the U.S. Census, 1980 to 2010." Population Research and Policy Review 32:663-686.

Jackson, Kenneth T. 1985. Crabgrass Frontier: The Suburbanization of the United States. New York: Oxford University Press.

Karlson, Kristian Bernt, Anders Holm, and Richard Breen. 2012. "Comparing Regression Coefficients between Same-Sample Nested Models Using Logit and Probit: A New Method." Sociological Methodology 42: 286-313.

Katz, Lawrence, Jeffrey Kling, and Jeffrey Liebman. 2001. "Moving to Opportunity in Boston: Early Results of a Randomized Mobility Experiment." The Quarterly Journal of Economics 116:607-54.

Keet, Corianne, Meredith C. McCormack, Craig E. Pollack, Roger D. Peng, Emily McGowan, and Elizabeth C. Matsui. 2015. "Neighborhood Poverty, Urban Residence, Race/Ethnicity, and Asthma: Rethinking the Inner-City Asthma Epidemic.” Journal of Allergy and Clinical Immunology 135:655-662.

Kramer, Michael R. and Carol R. Hogue. 2009. "Is Segregation Bad for Your Health?” Epidemiologic Reviews 31:178-194.

Krieger, James and Donna Higgins. 2002. "Housing and Health: Time Again for Public Action." American Journal of Public Health 92(7):758-68.

Logan, John R. 2011. "Separate and Unequal: The Neighborhood Gap for Blacks, Hispanics, and Asians in Metropolitan America." Census Brief Prepared for Project US2010. http://www.s4.brown.edu/us2010

Logan, John R. 2013. "The Persistence of Segregation in the $21^{\text {st }}$ Century Metropolis." City and Community 12: 160-168. 
Logan, John R. and Brian J. Stults. 2011. "The Persistence of Segregation in the Metropolis: New Findings from the 2010 Census." Census Brief Prepared for Project US2010. http://www.s4.brown.edu/us2010.

Massey, Douglas S. and Nancy A. Denton. 1993. American Apartheid: Segregation and the Making of the Underclass. Cambridge, MA: Harvard University Press.

Massey, Douglas S. and Jonathan Tannen. 2015. "A Research Note on Trends in Black Hypersegregation.” Demography 52:1025-1034.

Mehta, Neil K., Hedwig Lee, and Kelly R. Ylitalo. 2013. "Child Health in the United States: Recent Trends in Racial/Ethnic Disparities.” Social Science and Medicine 95: 6-15.

Mehta, Amar J., Daniel P. Dooley, John Kane, Margaret Reid, and Snehal N. Shah. 2018. "Subsidized Housing and Adult Asthma in Boston, 2010-2015." American Journal of Public Health 108(8):1059-65.

Mendoza, Fernando, Stephanie Ventura, Burciaga Valdez, Ricardo Castillo, Laura Escato Saldivar, Katherine Baisden, and Reynaldo Martorell. 1991. "Selected Measures of Health Status for Mexican-American, Mainland Puerto Rican, and Cuban-American Children." Journal of American Medical Association 265:227-32.

Northridge, Jennifer, Olivia F. Ramirez, Jeanette A. Stingone, and Luz Claudio. 2010. "The Role of Housing Type and Housing Quality in Urban Children with Asthma." Journal of Urban Health: Bulletin of the New York Academy of Medicine 87(2):211-224.

Osypuk, Theresa L. and Dolores Acevedo-Garcia. 2010. "Beyond Individual Neighborhoods: A Geography of Opportunity Perspective for Understanding Racial/Ethnic Health Disparities." Health and Place 16:1113-1123.

Patillo-McCoy, Mary. 1999. Black Picket Fences. Chicago, IL: University of Chicago Press.

Pearlman, Deborah N., Sally Zierler, Stephen Meersman, Hyun K. Kim, Samara I. Viner-Brown, and Colleen Caron. 2006. "Race Disparities in Childhood Asthma: Does Where You Live Matter?" Journal of the National Medical Association 98(2):239.

Quartagno, M. and J. Carpenter. 2017.jomo: A Package for Multilevel Joint Modeling Multiple Imputation. https://CRAN.R-project.org/package=jomo.

Rauh, Virginia A., Ginger R. Chew, and Robin S. Garfinkel. 2002. "Deteriorated Housing Contributes to High Cockraoch Allergen Levels in Inner-City Households." Environmental Health Perspectives 110(supplement 2):323-27. 
Riley, Alicia R. 2017. "Neighborhood Disadvantage, Residential Segregation, and Beyond Lessons for Studying Structural Racism and Health." Journal of Racial and Ethnic Health Disparities DOI 10.1007/s40615-017-0378-5.

Rosenbaum, Emily. 2008. "Racial/ethnic Differences in Asthma Prevalence: the Role of Housing and Neighborhood Environments.” Journal of Health and Social Behavior 49(2):131-45.

Rosenbaum, Emily and Samantha Friedman. 2001. "Differences in the Locational Attainment of Immigrant and Native-Born Households with Children in New York City." Demography $38(3): 337-348$.

Rosenbaum, Emily and Samantha Friedman. 2007. The Housing Divide: How Generations of Immigrants Fare in New York's Housing Market. New York, NY: New York University Press.

Rothwell, Jonathan and Douglas S. Massey. 2009. "The Effect of Density Zoning on Racial Segregation in U.S. Urban Areas." Urban Affairs Review 44(6):779-806.

Rubin, Donald B. 1987. Multiple Imputation for Nonresponse in Surveys. New York, NY: John Wiley \& Sons.

Rugh, Jacob S. and Douglas S. Massey. 2014. "Segregation in Post-Civil Rights America: Stalled Integration or the End of the Segregated Century?" DuBois Review 11(2):205232.

Sampson, Robert J. 2012. Great American City: Chicago and the Enduring Neighborhood Effect. Chicago, IL: University of Chicago Press.

Sampson, Robert J. and Patrick Sharkey. 2008. "Neighborhood Selection and the Social Reproduction of Concentrated Racial Inequality.” Demography 45(1):1-29.

Timberlake, Jeffrey M., Aaron J. Howell, and Amanda J. Staight. 2010. “Trends in the Suburbanization of Racial/Ethnic Groups in U.S. Metropolitan Areas, 1970 to 2000.” Urban Affairs Review 47:218-255.

Timberlake, Jeffrey M., and John Iceland. 2007. "Change in Racial and Ethnic Residential Inequality in American Cities, 1970-2000." City \& Community 6(4):335-365.

Turner, Margery A., Rob Santos, Diane K. Levy, Doug Wissoker, Claudia Aranda, and Rob Pitingolo. 2013. Housing Discrimination against Racial and Ethnic Minorities 2012. Washington, DC: U.S. Department of Housing and Urban Development.

U.S. Census Bureau. 2017. "Table 6 - Race and Hispanic Origin by Selected Age Groups." Projections for the United States: 2017-2060. Main Series. Washington, DC. 
U.S. Census Bureau and HUD (the U.S. Department of Housing and Urban Development). 2018. 2015 AHS Metropolitan Sample: Sample Design, Weighting, and Error Estimation. Washington, DC: U.S. Census Bureau, Department of Commerce.

U.S. Department of Health and Human Services, Health Resources and Services Administration, Maternal and Child Health Bureau. 2011. Child Health USA 2011. Rockville, Maryland: U.S. Department of Health and Human Services.

Vesper, Stephen, Charles Barnes, Christina E. Ciaccio, Alan Johanns, Kevin Kennedy, Johnna S. Murphy, Arcela Nunez-Alvarez, Megan T. Sandel, David Cox, Gary Dewalt, and Peter J. Ashley. 2013. "Higher Environmental Relative Moldiness Index (ERMI) Values Measured in Homes of Asthmatic Children in Boston, Kansas City, and San Diego." Journal of Asthma 50(2):155-161.

Williams David R., Michelle Sternthal, and Rosalind J. Wright. 2009. "Social Determinants: Taking the Social Context of Asthma Seriously." Pediatrics. 123(Supplement 3):S174S184.

Yang, Tse-Chuan. 2014. "Racial Segregation and Health Research: Future Needs for Racial Health Disparities Research." Working Paper. 
Table 1. Asthma Prevalence and Child, Residential, and Householder/Household Characteristics of Children (6-17), Overall and by Race/Ethnicity in Metropolitan Areas, 2015

\begin{tabular}{|c|c|c|c|}
\hline \multirow{3}{*}{ Variables } & \multicolumn{3}{|c|}{ Percent: } \\
\hline & Total & Whites & Blacks \\
\hline & (1) & (2) & (3) \\
\hline \multicolumn{4}{|l|}{ Asthma } \\
\hline Child (6-17) ever had asthma & 13.00 & 11.41 & $16.98 * * *$ \\
\hline \multicolumn{4}{|l|}{ Child-level characteristics } \\
\hline Black (ref. White) & 28.61 & ----- & ----- \\
\hline Male (ref. female) & 50.27 & 51.03 & $48.36^{*}$ \\
\hline Age (mean) & 11.30 & 11.33 & 11.22 \\
\hline \multicolumn{4}{|l|}{ Residential characteristics } \\
\hline \multicolumn{4}{|l|}{ Metropolitan residential segregation } \\
\hline Black-white index of dissimilarity (mean) & 65.34 & 64.75 & $66.81 * * *$ \\
\hline Black isolation index (mean) & 58.22 & 55.90 & $63.99 * * *$ \\
\hline Hypersegregation & 44.87 & 44.18 & 46.60 \\
\hline Number of maintenance deficiencies (mean) & 0.57 & 0.47 & $.81 * * *$ \\
\hline Renter & 34.26 & 22.26 & $64.21 * * *$ \\
\hline \multicolumn{4}{|l|}{ Year the unit was built } \\
\hline Before 1970 & 40.74 & 38.54 & $46.22 * * *$ \\
\hline Between 1970 and 2000 & 38.12 & 39.62 & $34.36 * * *$ \\
\hline In 2000 or later & 21.15 & 21.84 & $19.43 *$ \\
\hline Neighborhood has a lot of serious crime $(1=$ agree; $0=$ disagree $)$ & 8.74 & 4.03 & $20.51 * * *$ \\
\hline \multicolumn{4}{|l|}{ Region } \\
\hline Northeast & 26.59 & 25.96 & 28.15 \\
\hline Midwest & 22.70 & 23.57 & $20.53 * *$ \\
\hline South & 30.49 & 26.35 & $40.83 * * *$ \\
\hline West & 20.22 & 24.12 & $10.49 * * *$ \\
\hline \multicolumn{4}{|l|}{ Demographic and SES Characteristics of Householder/Household } \\
\hline Married household & 68.53 & 79.06 & $42.28 * * *$ \\
\hline Foreign-born householder & 13.79 & 10.41 & $22.22 * * *$ \\
\hline \multicolumn{4}{|l|}{ Education } \\
\hline Less than high school & 6.25 & 4.37 & $10.96^{* * *}$ \\
\hline High school degree & 19.79 & 18.00 & $24.24 * * *$ \\
\hline Some college education & 29.02 & 25.92 & $36.75 * * *$ \\
\hline Bachelor's degree or higher & 44.94 & 51.71 & $28.05 * * *$ \\
\hline Total household income (in 1,000 of dollars) (mean) & 115.22 & 137.30 & $60.00 * * *$ \\
\hline At least one smoker & 12.34 & 9.42 & $19.64 * * *$ \\
\hline $\mathrm{N}$ & 7105 & 5164 & 1941 \\
\hline
\end{tabular}

$* * * \mathrm{p}<.001 ; * * \mathrm{p}<.01 ; * \mathrm{p}<.05$

Note: Whites and Blacks refer to non-Hispanic whites and blacks. 
Table 2. Multilevel Models Predicting Pediatric Asthma of Children (6-17) by Measures of Residential Segregation in Metropolitan America, 2015

\begin{tabular}{|c|c|c|c|c|c|c|}
\hline \multirow[b]{3}{*}{ Variables } & \multicolumn{2}{|c|}{ Dissimilarity Index } & \multicolumn{2}{|c|}{ Isolation Index } & \multicolumn{2}{|c|}{ Hypersegregation } \\
\hline & Model 1 & Model 2 & Model 1 & Model 2 & Model 1 & Model 2 \\
\hline & $(1)$ & $(2)$ & (3) & (4) & $(5)$ & $(6)$ \\
\hline \multicolumn{7}{|l|}{ Child-level characteristics } \\
\hline Race -- Black (ref. white) & $\begin{array}{c}0.438 * * * \\
(0.026)\end{array}$ & $\begin{array}{c}-1.848 * * * \\
(0.383)\end{array}$ & $\begin{array}{c}0.438 * * * \\
(0.026)\end{array}$ & $\begin{array}{c}-1.718 * * * \\
(0.277)\end{array}$ & $\begin{array}{c}0.438 * * * \\
(0.026)\end{array}$ & $\begin{array}{c}0.220 \\
(0.262)\end{array}$ \\
\hline Gender -- Male (ref. females) & $\begin{array}{c}0.384 * * * \\
(0.024)\end{array}$ & $\begin{array}{c}0.375 * * * \\
(0.023)\end{array}$ & $\begin{array}{c}0.384 * * * \\
(0.024)\end{array}$ & $\begin{array}{c}0.375^{* * *} \\
(0.023)\end{array}$ & $\begin{array}{c}0.384 * * * \\
(0.024)\end{array}$ & $\begin{array}{c}0.375^{* * *} \\
(0.023)\end{array}$ \\
\hline Age & $\begin{array}{l}0.016 * \\
(0.004)\end{array}$ & $\begin{array}{l}0.016^{*} \\
(0.004)\end{array}$ & $\begin{array}{c}0.016^{*} \\
(0.004)\end{array}$ & $\begin{array}{l}0.016^{*} \\
(0.004)\end{array}$ & $\begin{array}{c}0.016^{*} \\
(0.004)\end{array}$ & $\begin{array}{c}0.016^{*} \\
(0.004)\end{array}$ \\
\hline \multicolumn{7}{|l|}{ Residential characteristics } \\
\hline Segregation (measured by variable in heading) & $\begin{array}{c}0.885 \\
(0.494)\end{array}$ & $\begin{array}{r}1.420^{* *} \\
(0.564)\end{array}$ & $\begin{array}{c}0.214 \\
(0.290)\end{array}$ & $\begin{array}{l}-0.024 \\
(0.398)\end{array}$ & $\begin{array}{l}0.246 \\
(0.141)\end{array}$ & $\begin{array}{c}0.555^{* * *} \\
(0.149)\end{array}$ \\
\hline Race of child*segregation & & $\begin{array}{c}3.392 * * * \\
(0.574)\end{array}$ & & $\begin{array}{c}3.722 * * * \\
(0.429)\end{array}$ & & $\begin{array}{c}0.158 \\
(0.475)\end{array}$ \\
\hline Number of maintenance deficiencies & $\begin{array}{c}0.191 * * * \\
(0.014)\end{array}$ & $\begin{array}{c}0.212 * * * \\
(0.014)\end{array}$ & $\begin{array}{c}0.191 * * * \\
(0.014)\end{array}$ & $\begin{array}{c}0.212 * * * \\
(0.014)\end{array}$ & $\begin{array}{c}0.191 * * * \\
(0.014)\end{array}$ & $\begin{array}{c}0.212 * * * \\
(0.014)\end{array}$ \\
\hline Housing tenure -- Renter (ref. owner) & $\begin{array}{c}-0.009 \\
(0.048)\end{array}$ & $\begin{array}{r}-0.004 \\
(0.049)\end{array}$ & $\begin{array}{l}-0.009 \\
(0.048)\end{array}$ & $\begin{array}{c}-0.004 \\
(0.049)\end{array}$ & $\begin{array}{l}-0.009 \\
(0.048)\end{array}$ & $\begin{array}{c}-0.004 \\
(0.049)\end{array}$ \\
\hline \multicolumn{7}{|l|}{ Year the unit was built (ref. before 1970) } \\
\hline Between 1970 and 2000 & $\begin{array}{c}0.072 \\
(0.032)\end{array}$ & $\begin{array}{c}0.080 \\
(0.032)\end{array}$ & $\begin{array}{c}0.072 \\
(0.032)\end{array}$ & $\begin{array}{c}0.080 \\
(0.032)\end{array}$ & $\begin{array}{c}0.072 \\
(0.032)\end{array}$ & $\begin{array}{c}0.080 \\
(0.032)\end{array}$ \\
\hline In 2000 or later & $\begin{array}{c}-0.345^{* * *} \\
(0.032)\end{array}$ & $\begin{array}{c}-0.326^{* * *} \\
(0.030)\end{array}$ & $\begin{array}{c}-0.345 * * * \\
(0.032)\end{array}$ & $\begin{array}{c}-0.326^{* * *} \\
(0.030)\end{array}$ & $\begin{array}{c}-0.345^{* * *} \\
(0.032)\end{array}$ & $\begin{array}{c}-0.326^{* * *} \\
(0.030)\end{array}$ \\
\hline $\begin{array}{l}\text { Neighborhood has a lot of serious crime } \\
\quad(1=\text { agree; } 0=\text { disagree })\end{array}$ & $\begin{array}{l}0.156^{*} \\
(0.037)\end{array}$ & $\begin{array}{c}0.209^{* *} \\
(0.034)\end{array}$ & $\begin{array}{l}0.156^{*} \\
(0.037)\end{array}$ & $\begin{array}{l}0.209 * * \\
(0.034)\end{array}$ & $\begin{array}{l}0.156^{*} \\
(0.037)\end{array}$ & $\begin{array}{c}0.209 * * \\
(0.034)\end{array}$ \\
\hline \multicolumn{7}{|l|}{ Region } \\
\hline Midwest (ref. Northeast) & $\begin{array}{l}-0.153 \\
(0.284)\end{array}$ & $\begin{array}{l}-0.461 \\
(0.298)\end{array}$ & $\begin{array}{l}-0.152 \\
(0.284)\end{array}$ & $\begin{array}{r}-0.460 \\
(0.298)\end{array}$ & $\begin{array}{l}-0.153 \\
(0.283)\end{array}$ & $\begin{array}{l}-0.461 \\
(0.297)\end{array}$ \\
\hline South & $\begin{array}{c}0.006 \\
(0.287)\end{array}$ & $\begin{array}{r}-0.051 \\
(0.288)\end{array}$ & $\begin{array}{c}0.005 \\
(0.287)\end{array}$ & $\begin{array}{l}-0.051 \\
(0.289)\end{array}$ & $\begin{array}{c}0.006 \\
(0.287)\end{array}$ & $\begin{array}{l}-0.051 \\
(0.288)\end{array}$ \\
\hline West & $\begin{array}{c}0.035 \\
(0.266)\end{array}$ & $\begin{array}{l}-0.034 \\
(0.262)\end{array}$ & $\begin{array}{l}-0.007 \\
(0.225)\end{array}$ & $\begin{array}{l}-0.128 \\
(0.260)\end{array}$ & $\begin{array}{l}0.039 \\
(0.271)\end{array}$ & $\begin{array}{c}0.051 \\
(0.250)\end{array}$ \\
\hline
\end{tabular}

$* * * \mathrm{p}<.001 ; * * \mathrm{p}<.01 ; * \mathrm{p}<.05$ 
Table 2 (cont'd). Multilevel Models Predicting Pediatric Asthma of Children (6-17) by Measures of Residential Segregation in Metropolitan America, 2015

\begin{tabular}{|c|c|c|c|c|c|c|}
\hline \multirow[b]{3}{*}{ Variables } & \multicolumn{2}{|c|}{ Dissimilarity Index } & \multicolumn{2}{|c|}{ Isolation Index } & \multicolumn{2}{|c|}{ Hypersegregation } \\
\hline & Model 1 & Model 2 & Model 1 & Model 2 & Model 1 & Model 2 \\
\hline & $(1)$ & $(2)$ & (3) & $(4)$ & $(5)$ & $(6)$ \\
\hline \multicolumn{7}{|l|}{$\begin{array}{l}\text { Demographic and SES Characteristics of } \\
\text { Householder/Household }\end{array}$} \\
\hline Married household & $\begin{array}{c}-0.114 * * * \\
(0.011)\end{array}$ & $\begin{array}{c}-0.101 * * * \\
(0.011)\end{array}$ & $\begin{array}{c}-0.114 * * * \\
(0.011)\end{array}$ & $\begin{array}{c}-0.101 * * * \\
(0.011)\end{array}$ & $\begin{array}{c}-0.114 * * * \\
(0.011)\end{array}$ & $\begin{array}{c}-0.101 * * * \\
(0.011)\end{array}$ \\
\hline Foreign-born householder & $\begin{array}{c}-0.504 * * * \\
(0.039)\end{array}$ & $\begin{array}{r}-0.442 * * \\
(0.044)\end{array}$ & $\begin{array}{c}-0.504 * * * \\
(0.039)\end{array}$ & $\begin{array}{r}-0.442 * * \\
(0.044)\end{array}$ & $\begin{array}{c}-0.504 * * * \\
(0.039)\end{array}$ & $\begin{array}{r}-0.442 * * \\
(0.044)\end{array}$ \\
\hline \multicolumn{7}{|l|}{ Education (ref. less than high school degree) } \\
\hline High school degree & $\begin{array}{c}-0.262 * * \\
(0.052)\end{array}$ & $\begin{array}{c}-0.317 * * \\
(0.054)\end{array}$ & $\begin{array}{c}-0.262 * * \\
(0.052)\end{array}$ & $\begin{array}{c}-0.317 * * \\
(0.054)\end{array}$ & $\begin{array}{c}-0.262 * * \\
(0.052)\end{array}$ & $\begin{array}{c}-0.317 * * \\
(0.054)\end{array}$ \\
\hline Some college education & $\begin{array}{l}-0.087 \\
(0.043)\end{array}$ & $\begin{array}{l}-0.131^{*} \\
(0.045)\end{array}$ & $\begin{array}{l}-0.087 \\
(0.043)\end{array}$ & $\begin{array}{c}-0.131 * \\
(0.045)\end{array}$ & $\begin{array}{l}-0.087 \\
(0.043)\end{array}$ & $\begin{array}{c}-0.131 * \\
(0.045)\end{array}$ \\
\hline Bachelor's degree or more & $\begin{array}{c}-0.414^{* * *} \\
(0.029)\end{array}$ & $\begin{array}{c}-0.438 * * * \\
(0.029)\end{array}$ & $\begin{array}{c}-0.414 * * * \\
(0.029)\end{array}$ & $\begin{array}{c}-0.438 * * * \\
(0.029)\end{array}$ & $\begin{array}{c}-0.414 * * * \\
(0.029)\end{array}$ & $\begin{array}{c}-0.438 * * * \\
(0.029)\end{array}$ \\
\hline Total household income (in 1,000 of dollars) & $\begin{array}{c}0.001 * * * \\
(0.000)\end{array}$ & $\begin{array}{c}0.001 * * * \\
(0.000)\end{array}$ & $\begin{array}{c}0.001 * * * \\
(0.000)\end{array}$ & $\begin{array}{c}0.001 * * * \\
(0.000)\end{array}$ & $\begin{array}{c}0.001 * * * \\
(0.000)\end{array}$ & $\begin{array}{c}0.001 * * * \\
(0.000)\end{array}$ \\
\hline At least one smoker & $\begin{array}{r}-0.210^{*} \\
(0.048)\end{array}$ & $\begin{array}{c}-0.181^{*} \\
(0.047)\end{array}$ & $\begin{array}{r}-0.210^{*} \\
(0.048)\end{array}$ & $\begin{array}{r}-0.181^{*} \\
(0.047)\end{array}$ & $\begin{array}{c}-0.210 * \\
(0.048)\end{array}$ & $\begin{array}{r}-0.181^{*} \\
(0.047)\end{array}$ \\
\hline Intercept & $\begin{array}{c}-2.816^{* * *} \\
(0.425)\end{array}$ & $\begin{array}{c}-3.118 * * * \\
(0.435)\end{array}$ & $\begin{array}{c}-2.365 * * * \\
(0.203)\end{array}$ & $\begin{array}{c}-2.192 * * * \\
(0.262)\end{array}$ & $\begin{array}{l}-2.342 * * * \\
(0.219)\end{array}$ & $\begin{array}{c}-2.433 * * * \\
(0.208)\end{array}$ \\
\hline
\end{tabular}

$* * * \mathrm{p}<.001 ; * * \mathrm{p}<.01 ; * \mathrm{p}<.05$ 
Figure 1. Predicted Probabilities of Asthma for White and Black Children by D-Scores

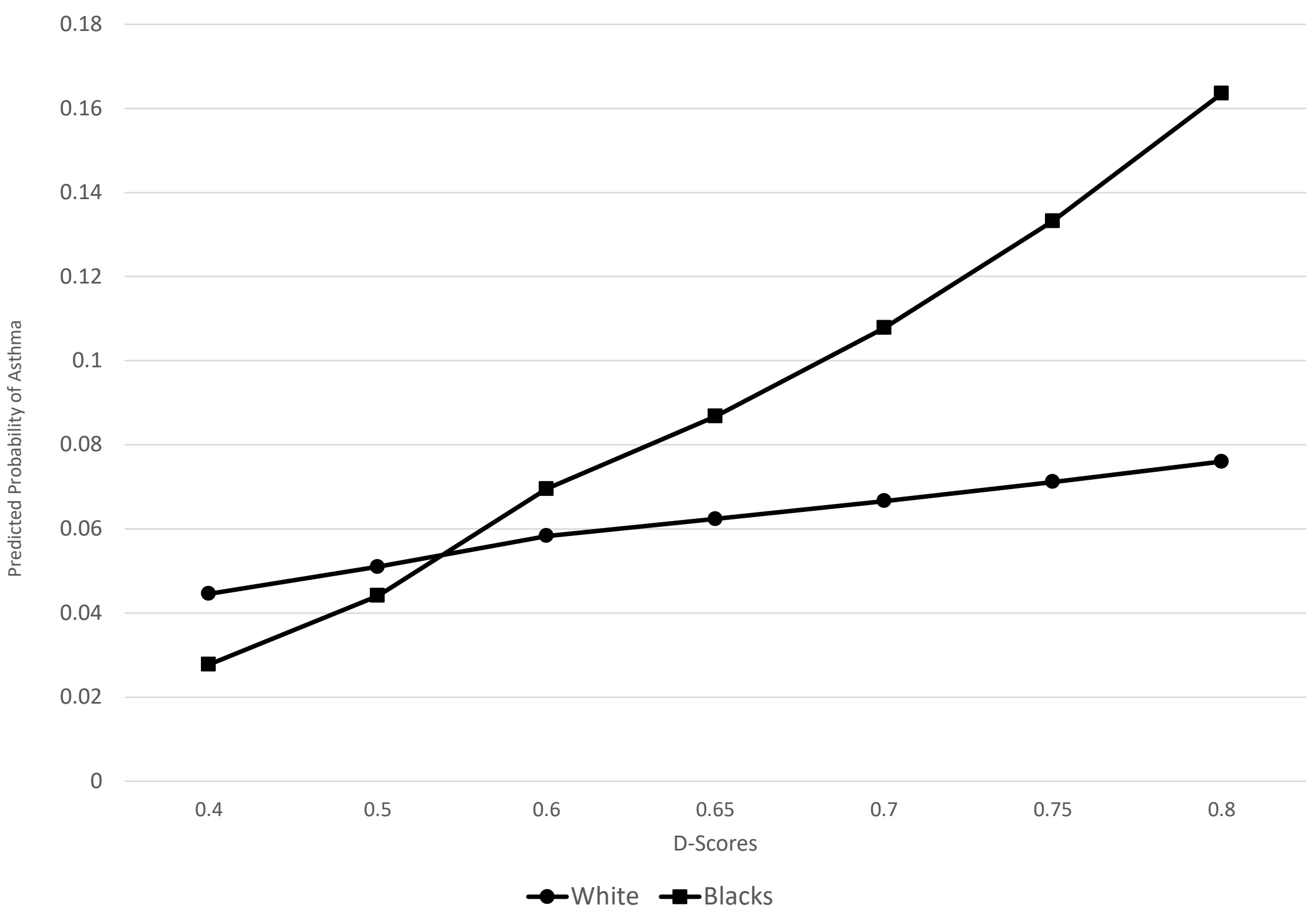


Figure 2. Predicted Probabilities of Asthma for White and Black Children

by Black Isolation Scores

0.2

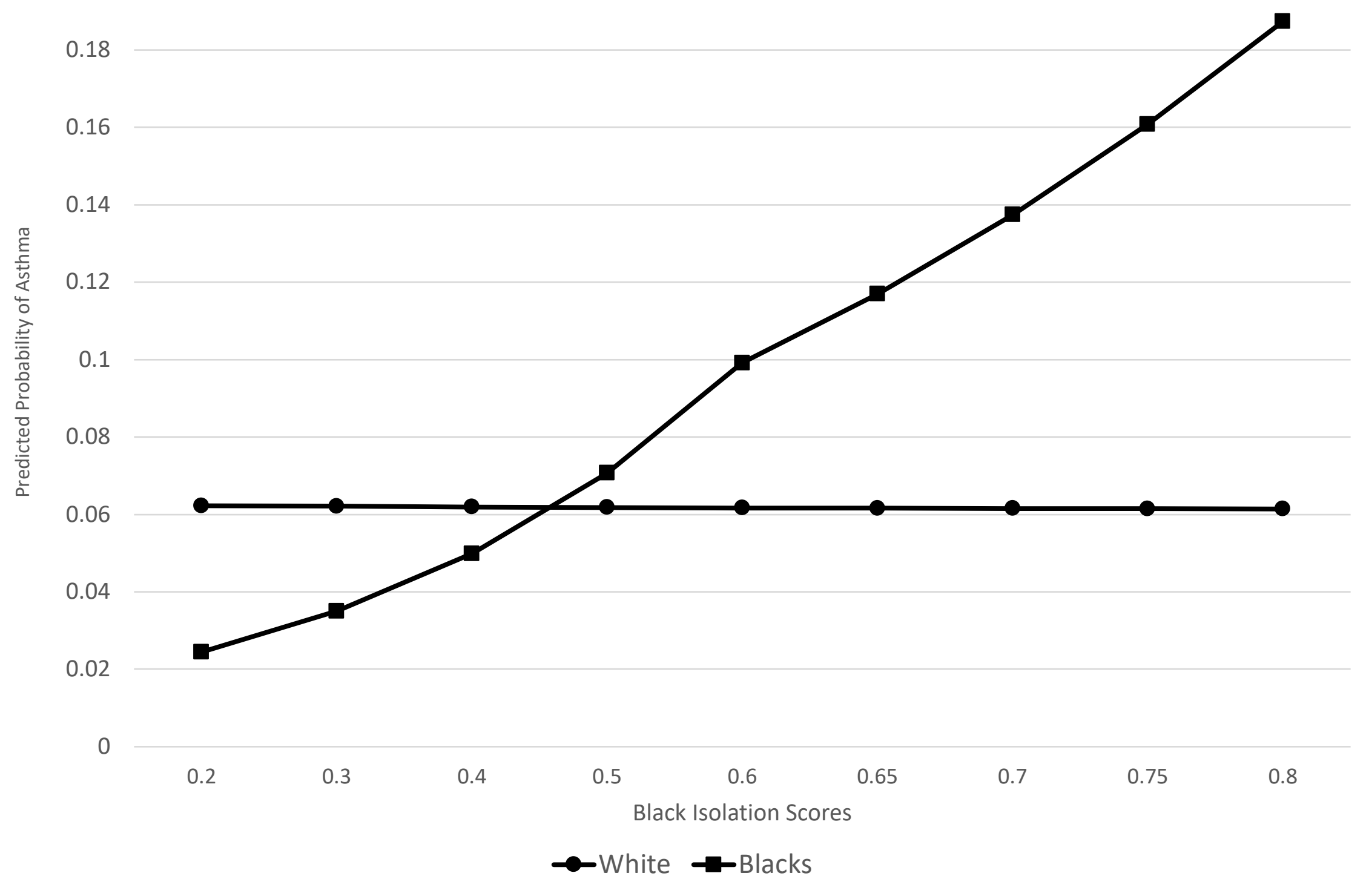


2010 Census Data

2015 ACS Data

\begin{tabular}{|c|c|c|c|c|c|}
\hline Metropolitan Area & $\begin{array}{c}\text { Black- } \\
\text { White D- } \\
\text { Score } \\
\end{array}$ & $\begin{array}{c}\text { Black } \\
\text { Isolation } \\
\text { Index } \\
\end{array}$ & $\begin{array}{c}\text { B-W Hyper- } \\
\text { Segregated } \\
\text { Area } \\
\left(^{\text {Yes } / \text { No })^{a}}\right. \\
\end{array}$ & $\begin{array}{c}\text { Black } \\
\text { Population }\end{array}$ & $\begin{array}{c}\text { Percent } \\
\text { Black }\end{array}$ \\
\hline Milwaukee-Waukesha-West Allis, WI & 81.52 & 73.47 & Yes & 257,063 & 16.31 \\
\hline New York-Newark-Jersey City, NY-NJ-PA & 77.31 & 73.55 & Yes & $3,172,787$ & 15.72 \\
\hline Chicago-Naperville-Elgin, IL-IN-WI & 76.43 & 73.77 & Yes & $1,574,907$ & 16.49 \\
\hline Detroit-Warren-Dearborn, MI & 75.25 & 73.47 & Yes & 960,601 & 22.33 \\
\hline Cleveland-Elyria, $\mathrm{OH}$ & 74.14 & 68.40 & Yes & 406,575 & 19.73 \\
\hline Cincinatti, OH-KY-IN & 69.30 & 51.67 & No & 258,786 & 11.98 \\
\hline Philadelphia-Camden-Wilmington, PA-NJ-DE-MD & 68.41 & 65.15 & Yes & $1,218,789$ & 20.08 \\
\hline Los Angeles-Long Beach-Anaheim, CA & 67.84 & 61.01 & No & 863,556 & 6.47 \\
\hline Pittsburgh, PA & 65.75 & 43.25 & No & 186,338 & 7.92 \\
\hline Miami-Fort Lauderdale-West Palm Beach, FL & 64.83 & 68.46 & No & $1,224,160$ & 20.36 \\
\hline Boston-Cambridge-Newton, MA-NH & 64.02 & 44.24 & Yes & 351,997 & 7.37 \\
\hline New Orleans-Metairie, LA & 63.41 & 68.87 & No & 434,291 & 34.39 \\
\hline Denver-Aurora-Lakewood, CO & 62.59 & 31.31 & No & 150,357 & 5.34 \\
\hline Memphis, TN-MS-AR & 62.31 & 73.27 & No & 622,619 & 46.34 \\
\hline Washington-Arlington-Alexandria, DC-VA-MD & 62.10 & 65.53 & No & $1,510,280$ & 24.77 \\
\hline San Francisco-Oakland-Hayward, CA & 62.00 & 47.48 & No & 341,209 & 7.33 \\
\hline Houston-The Woodlands-Sugar Land, TX & 61.49 & 61.71 & No & $1,122,767$ & 16.87 \\
\hline Kansas City, MO-KS & 61.10 & 49.97 & Yes & 259,181 & 12.41 \\
\hline Atlanta-Sandy Springs-Roswell, GA & 58.91 & 65.61 & No & $1,892,415$ & 33.14 \\
\hline Dallas-Fort Worth-Arlington, TX & 56.88 & 52.15 & No & $1,076,803$ & 15.16 \\
\hline Seattle-Tacoma-Bellevue, WA & 49.11 & 20.74 & No & 205,698 & 5.51 \\
\hline Portland-Vancouver-Hillsboro, OR-WA & 45.69 & 11.00 & No & 65,003 & 2.72 \\
\hline Riverside-San Bernardino-Ontario, CA & 45.69 & 32.46 & No & 309,789 & 6.90 \\
\hline Phoenix-Mesa-Scottsdale, AZ & 43.63 & 19.63 & No & 233,171 & 5.10 \\
\hline Raleigh, NC & 42.11 & 41.91 & No & 253,598 & 19.91 \\
\hline
\end{tabular}

${ }^{a}$ We use Massey and Tannen's (2015) classification of scoring high on at least four dimensions of segregation to determine if the metropolitan area is hypersegregated.

Note: The table is sorted in descending order by the index of dissimilarity.

Sources: Authors' tabulations of Census 2010 data and ACS 2015 data 
